\title{
Exploring the Effectiveness of PAC Rehabilitation for Elders with Hip Surgery: A Retrospective Study
}

\author{
Ju-Lan Yang ${ }^{1,2, *}$ \\ Yang-Hao Ou ${ }^{3, *}$ \\ Sen-Yung Liu' \\ Ching-Hsiung $\operatorname{Lin}^{4-6}$ \\ Shu-Wei Chang $\mathbb{1}^{7}$ \\ Yueh-Hsiu Lu ${ }^{8}$ \\ Taishan Shen ${ }^{8}$ \\ Cheng-Pu Hsieh ${ }^{8}$ \\ Chih-Ming Lin (1D) ${ }^{3}$ \\ Ruoh-Lih Lei ${ }^{2}$
}

'Department of Physical Medicine and Rehabilitation, Changhua Christian

Hospital, Changhua, Taiwan; ${ }^{2}$ Department

of Nursing, College of Nursing, Hungkuang

University, Taichung, Taiwan; ${ }^{3}$ Department

of Neurology, Changhua Christian Hospital,

Changhua, Taiwan; ${ }^{4}$ Division of Chest

Medicine, Department of Internal

Medicine, Changhua Christian Hospital,

Changhua, Taiwan; ${ }^{5}$ Institute of Genomics and Bioinformatics, National Chung Hsing

University, Taichung, Taiwan; ${ }^{6}$ Department of Recreation and Holistic Wellness,

MingDao University, Changhua, Taiwan;

${ }^{7}$ Department of Medicinal Botanicals and

Health Applications, Dayeh University,

Changhua, Taiwan; ${ }^{8}$ Department of

Orthopedic Surgery, Changhua Christian

Hospital, Changhua, Taiwan

*These authors contributed equally to this work

Correspondence: Chih-Ming Lin

Department of Neurology, Changhua

Christian Hospital, No. 135, Nanxiao

Street, Changhua City, Changhua County,

500, Taiwan

Email166110@cch.org.tw

Ruoh-Lih Lei

Department of Nursing, College of Nursing, Hungkuang University, No. 1018 ,

Sec. 6, Taiwan Boulevard, Shalu Dist.,

Taichung City, 43302, Taiwan

Email lilylei@hk.edu.tw
Background: Hip fractures are high risk and high-impact events in the elderly population; despite orthopedic hip surgery, the disability and mortality rate remains significant. The National Health Insurance Agency in Taiwan established a fragility fracture PAC rehabilitation program to provide functional recovery for these patients after the surgery. However, the current literature on PAC rehabilitation is outdated, and there is an urgent need for the reevaluation of the program.

Methods: This is a retrospective cohort study that enrolled 159 patients in the PAC rehabilitation program, followed by hip repair surgery. Outcome measures were the differences in participants' pre- and post-PAC scores in 1) Barthel index, 2) Numerical Rating Scale (NRS), and 3) Harris Hip Scores (HHS) as surrogate indicators of the functional status, followed by the analysis of subgroups, including sex, age, site of the fracture, type of procedure, and the number of comorbidities.

Results: After completing PAC rehabilitation, $86.2 \%$ of the patients successfully returned to the community with either home or out-patient rehabilitation. The re-admission rate was $3.1 \%$ and $3.8 \%$ in 14 -days and in 30-days follow up, respectively. The difference in pre- and post-Barthel index, NRS, and HHS showed significant improvement $(p<0.001)$, without significant variations between the subgroups. Additionally, the Barthel index showed a positive correlation to HHS and a negative correlation to NRS.

Conclusion: This study revealed that the current form of post-surgery fragility fracture PAC program effectively improves functional status, reduces the re-admission rate, and facilitates the patient transition back to the community. The results should improve patients' and physicians' confidence in such a program.

Keywords: post-acute care, rehabilitation, hip fracture, Barthel index, Harris Hip Score

\section{Introduction}

Hip fracture is a major cause of disabilities in the elderly worldwide; the number of hip fracture cases will increase from 1.26 million in 1990 to 4.5 million in $2020 .{ }^{1}$ A study was conducted using the Taiwanese National Health Insurance database and showed that more than fifty-thousand patients were admitted to the hospital with a diagnosis of hip fracture between the years 1996 to $2000 .^{2}$ The consequences of hip fractures are often reflected in the deterioration of the quality of $\mathrm{life}^{3}$ due to limited physical and social function. While the annual mortality rate from hip fracture has declined from $18 \%$ to $14 \%$ from the year 1999 to 2009 in Taiwan, ${ }^{4}$ however, the relative risk can be as high as double of the general population, and the risk remains high even after ten years follow up. ${ }^{5,6}$ The adjusted long-term mortality risk is attributed to the exacerbated frailty in these patients. ${ }^{7}$ 
Traditionally, patients who underwent hip surgery were discharged home a few days after the operation; the hasty discharge left patients and families exiguous time and resources to arrange subsequent rehabilitation. ${ }^{8}$ In 2010, the National Health Insurance Agency (NHIA) adopted the Diagnosis Related Groups (TW-DRGs) bundled payment system to encourage the quality of care improvement while keeping healthcare cost-effective. ${ }^{9}$ Medical centers adopted to this policy by limiting the length of stay to five to seven days after the hip repair surgery to remain profitable and shift the responsibilities of post-operative care and rehabilitation to community hospitals by forming alliances and developing the so-called post-acute care (PAC) programs.

The NHIA oversaw the PAC program and planned a step-wise implementation, started with the acute stroke PAC (PAC-CVD) in 2014, the burnt injury PAC in 2015, the frail elders, chronic heart failure, traumatic neurologic injury, and post-surgical fragility fracture PACs in 2017. PAC programs serve as a transition zone between the hospital and the community; it provides necessary rehabilitation and cares for the patients while allowing their families to have an adequate breathing room and post-discharge planning time. The critical difference between the traditional inhospital and the PAC rehabilitation is the structured and multi-disciplinary team, involving physicians, physical and occupational therapists, nurses, social workers, and medical and nutritional councilors. PAC patients also have an intensified and individualized rehabilitation schedule. The average rehabilitation time one received during the initial hospitalization was approximately twenty minutes per day for five to seven days; on the other hand, PACs can provide as much as one-hour session twice a day, therefore, greatly improved the potential in recovery. Additionally, a study conducted in Taiwan had shown that there was a significant reduction in re-admission and mortality rate when a frail elderly was transferred to PAC instead of directly returning home. ${ }^{10}$ Besides the health benefits, the PAC facility's cost of care is significantly lower than in the medical center, both in the United States ${ }^{11}$ and in Taiwan. ${ }^{12}$

As opposed to the well-established acute stroke PAC rehabilitation program in $2014,{ }^{13}$ sophisticated guidance has not been constructed for the post-surgical fragility fracture PAC rehabilitation. Literature view found outdated studies on surgical PAC before implementing the fragility fracture PAC program, and most of the published papers enrolled subjects prior to 2017. This study aims to provide an up-to-date evaluation of the effectiveness of rehabilitation programs in PAC in the recovery of the functional status in patients with hip fracture surgery. Functional status was measured using the Barthel index, Numerical Rating Scale (NRS), the Harris Hip Score (HHS), and followed by assessing the patient's condition one month after discharge from the PAC, including readmission rate and subsequent disposition of the patients.

\section{Method}

The Institutional Review Board of a tertiary medical center approved this retrospective medical chart review and analysis.

\section{Study Design and Sample Selection}

This study was conducted in the PAC rehabilitation ward affiliated with a tertiary medical center in Changhua City, Taiwan. The inclusion criteria were: 1) patients with hip fracture repair (ORIF, bipolar hemiarthroplasty, total hip replacement) within one month, 2) age $\geqq 65$ years old, 3) a decrease in Barthel index (scores between 40 and 70), 4) no acute complications or stabilized through medical therapy, 5) stable condition without the need of frequent evaluation or supervision, 6) without oxygen supplement of any form (nasal cannula, mask or others), 7) deemed excellent recovery potential through rehabilitation by the clinician, 8) acquired informed consent and sufficient support by the family.

The exclusion criteria include patients with 1) vertebral fracture with spinal cord injury, 2) severe cognitive impairment, 3) severe psychiatric conditions, 4) requiring any form of ventilation machine, 5) terminal diseases, 6) disabled without the possibility of getting out of bed, and 7) cancer patients requiring chemotherapy or radiotherapy.

\section{Statistical Analysis}

This study enrolled a total of 159 participants with complete demographic information and baseline measurements. The medical record should include assessment in three domains: 1) functional outcome (Barthel index), 2) pain scale using the Numerical Rating Scale (NRS), and 3) Hip fracture assessment using the Harris Hip Score (HHS).

These assessments were both performed before and after receiving the rehabilitation in PAC. By using the paired sample $t$-test to compute the differences between the pre- and post-PAC scores. The Mann-Whitney $U$-test or Kruskal Wallis Test was used to examining whether these changes are significantly different among the subgroups. Statistical analysis was carried out using IBM 
SPSS Statistics for Windows, Version 25.0 (IBM Corp, Armonk, NY).

\section{Results}

The current study included a total of 159 participants; the baseline characteristics are summarized in Table 1. There were 115 females $(72.3 \%)$ and 44 males $(27.7 \%)$, the average age of the participants was $79.97 \pm 7.5$ years old, and the majority of them were married $(n=106,66.7 \%)$. Most participants received no education or up to elementary school level $(\mathrm{n}=127,79.9 \%)$, and only 13 people achieved college education (8.2\%).

Table I Baseline Demographic Study

\begin{tabular}{|c|c|c|c|}
\hline \multicolumn{2}{|c|}{ Baseline Characteristics } & \multicolumn{2}{|c|}{$\begin{array}{c}\text { (Total } \\
N=159)\end{array}$} \\
\hline & & \multirow{2}{*}{$\frac{\mathbf{N}}{115}$} & \multirow{2}{*}{\begin{tabular}{|c|}
$\%$ \\
72.3
\end{tabular}} \\
\hline Sex & Female & & \\
\hline & Male & 44 & 27.7 \\
\hline \multirow[t]{3}{*}{ Age } & $65-74$ & 39 & 24.5 \\
\hline & $75-84$ & 69 & 43.4 \\
\hline & $\geqq 85$ & 51 & 32.1 \\
\hline \multirow[t]{2}{*}{ Marital status } & Married & 106 & 66.7 \\
\hline & Single & 53 & 33.3 \\
\hline \multirow[t]{4}{*}{ Education level } & None/elementary school & 127 & 79.9 \\
\hline & Jr. high school & 7 & 4.4 \\
\hline & High school & 12 & 7.5 \\
\hline & College or above & 13 & 8.2 \\
\hline \multirow[t]{2}{*}{ Site of fracture } & $\begin{array}{l}\text { Femoral tuberosity/proximal } \\
\text { femoral epiphyses }\end{array}$ & 64 & 40.3 \\
\hline & Femoral neck/head & 95 & 59.7 \\
\hline \multirow[t]{3}{*}{ Type of procedure } & ORIF & 104 & 65.4 \\
\hline & BIPOLAR & 50 & 31.4 \\
\hline & THR & 5 & 3.1 \\
\hline \multirow{3}{*}{$\begin{array}{l}\text { Numbers of co- } \\
\text { morbidities }\end{array}$} & 0 & 14 & 8.8 \\
\hline & 1 & 39 & 24.5 \\
\hline & $\geqq 2$ & 106 & 66.7 \\
\hline \multirow{2}{*}{$\begin{array}{l}\text { I4-day re- } \\
\text { admission }\end{array}$} & No & 154 & 96.9 \\
\hline & Yes & 5 & 3.1 \\
\hline \multirow{2}{*}{$\begin{array}{l}\text { 30-day re- } \\
\text { admission }\end{array}$} & No & 153 & 96.2 \\
\hline & Yes & 6 & 3.8 \\
\hline \multirow{4}{*}{$\begin{array}{l}\text { Post-PAC } \\
\text { disposition }\end{array}$} & Home rehabilitation & 27 & 17 \\
\hline & Out-patient rehabilitation & 110 & 69.2 \\
\hline & Institutionalized & 13 & 8.2 \\
\hline & Re-admission & 9 & 5.6 \\
\hline
\end{tabular}

Abbreviations: THR, Total hip replacement; BIPOLAR, Bipolar hemiarthroplasty; ORIF, Open reduction internal fixation.
In terms of the fracture site, 95 patients $(59.7 \%)$ had femoral neck or femoral head fractures, and 64 patients (40.3\%) had femoral tuberosity or proximal femoral epiphyses. A total of 104 patients (65.4\%) underwent internal fixation, 50 (31.4\%) underwent Bipolar hemiarthroplasty, and $5(3.1 \%)$ underwent a total hip replacement. Most participants $(n=106,66.7 \%)$ have two or more comorbidities, $24.5 \%$ with one comorbidity and only $8.8 \%$ have no chronic conditions.

In the examination comorbidities, over two-thirds of the patients have hypertension, and close to one-third with diabetes mellitus (Figure 1). Other co-morbidities in decreasing order are cardiovascular diseases (15.7\%), kidney diseases $(7.5 \%)$, malignancies $(6.3 \%)$, asthma/COPD $(5 \%)$, liver diseases $(3.1 \%)$, psychiatric conditions $(1.9 \%)$, and seizure disorders $(1.3 \%)$.

Follow-up on participants' disposition showed that only five patients were re-admitted to the hospital within fourteen days and six patients re-admitted during the onemonth follow-up. After completing PAC rehabilitation, the majority of the patients successfully returned to the community, where they continued the rehabilitation process either at home $(\mathrm{n}=27)$ or in an out-patient setting $(\mathrm{n}=$ 110). Only thirteen patients were subsequently transferred to a long-term institution, and nine patients re-admitted to the hospital (Table 1).

Table 2 shows the average scores of the three batteries before and after completion of the PAC rehabilitation program. The average pre-PAC Barthel index was $46.98 \pm 8.25$, and after completion of the rehabilitation program, participants improved significantly with an average score of 62.74 \pm 12.49 ( $\mathrm{p}<0.001)$. Similarly, the average pre-PAC HHS was $35.11 \pm 12.75$ that increased to $47.92 \pm 13.71(\mathrm{p}<0.001)$ in the post-PAC assessment. Additionally, the participants' pain showed significant amelioration after discharge.

Table 3 is the sub-group analysis by breaking down the participants by their sex, age, fracture site, types of surgical procedure, and the number of comorbidities. The results found that none of these subgroups had a significant impact on the outcome measurements.

Table 4 results from the Pearson product-moment correlation coefficient analysis of the relationship between the Barthel index, NRS, and HHS. The pre-, post-PAC, and the score differences (post minus pre-PAC score) were included in this analysis. The pre- and post-PAC Barthel index was found positively correlated to its respective HHS score $(\mathrm{p}<0.05)$ and correlate negatively to its respective NRS scores $(\mathrm{p}<0.01)$. 


\section{Distribution of co-morbidities}

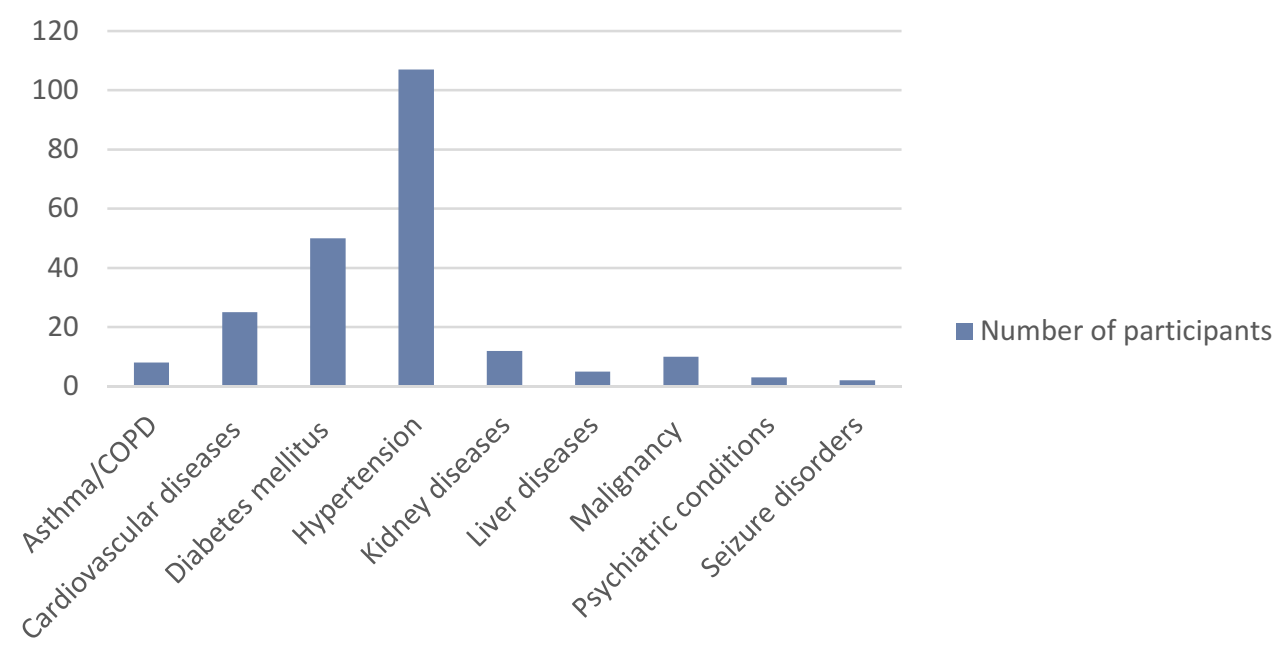

Figure I Distribution of co-morbidities among participants.

\section{Discussion}

Hip fracture is a high risk and disabling event for the elderly, and surgical repair remains the definitive intervention. However, these patients require post-operative rehabilitation to facilitate returning to the community. Although the link between rehabilitation and functional status after hip surgery has been well established, healthcare behavior has been continuously evolving to adopt the TW-DRG since the implementation in 2010. In this study, we re-examine the current clinical practice and the effectiveness of rehabilitation in the PAC setting.

This study was conducted in a tertiary medical center with a well-established PAC network. We included 159 patients who underwent orthopedic surgeries for hip fractures; they were subsequently transferred to PAC for extended rehabilitation and followed up for one month after discharge.

In the present study, females are more likely to suffer from hip fractures; this finding is consistent with Karagas et al, a nationwide population-based cohort

Table 2 Analysis of the pre- and Post-PAC Scores in Barthel Index, NRS, and HHS

\begin{tabular}{|l|l|l|l|}
\hline $\begin{array}{l}\text { Assessment } \\
\text { Batteries }\end{array}$ & $\begin{array}{l}\text { Pre-PAC } \\
\text { Score }\end{array}$ & $\begin{array}{l}\text { Post-PAC } \\
\text { Score }\end{array}$ & P-value \\
\hline Barthel index & $46.98 \pm 8.25$ & $62.74 \pm 12.49$ & $<0.001$ \\
NRS & $3.92 \pm I .4 I$ & $2.58 \pm 1.27$ & $<0.001$ \\
HHS & $35.1 I \pm I 2.75$ & $47.92 \pm 13.7 I$ & $<0.00 I$ \\
\hline
\end{tabular}

Notes: Paired Sample t-test. $\mathrm{N}=159$. study in Taiwan. Approximately sixty percent of the participants had a femoral neck fracture; this finding is in concordance with white women. ${ }^{14}$ To the authors' knowledge, while there were many studies reported on the effectiveness of PAC-CVD in Taiwan, but there is a lack of data for the post-hip surgery PAC programs. However, the current study's key results are comparable to that of studies on PAC-CVD in Taiwan. The reason for including Barthel index $(40-70)$ for the current study is because of demonstration of full compliance of the patients during the hospitalization. The "milder" or "severer" patients are excluded as they could not reflect the genuine effects after patients receiving the PAC program. The included study participants are motivated and keen to return to premorbid state. This interaction is also documented in our daily life training from staff members of department of Physical Medicine and Rehabilitation.

After completing the PAC rehabilitation, a majority of the patients returned to the community and continued rehabilitation either at home $(\mathrm{n}=27,17 \%)$ or in an outpatient clinic $(\mathrm{n}=110,69.2 \%)$. Additionally, the readmission rate remains low in both 14-days $(n=5$, $3.1 \%)$ and 30 -days $(\mathrm{n}=6,3.8 \%)$ follow up. This finding was similar to another cohort study in Taiwan, where it showed as high as $76.8 \%$ of the patients successfully returned to their home or community after completion of the PAC-CVD program; and the 14-days re-admission rate was $5.6 \%{ }^{15}$ 


\begin{tabular}{|c|c|c|c|c|c|c|c|}
\hline \multirow{4}{*}{ 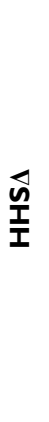 } & $\begin{array}{l}\frac{0}{2} \\
\frac{2}{N} \\
\frac{1}{2} \\
a\end{array}$ & & $\frac{m}{\overline{0}}$ & $\begin{array}{c}\text { ○े } \\
\infty \\
0\end{array}$ & $\stackrel{\substack{\tilde{n} \\
0}}{o}$ & ָ̊ & 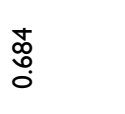 \\
\hline & $\underset{\mathbf{x}}{\mathbf{x}}$ & $\bar{\forall}$ & $\bar{\sigma}$ & $\bar{\sigma}$ m 우 & 웋 ₹ & $\bar{m}$ & ‡ \\
\hline & $\frac{\Xi}{\Sigma}$ & $\stackrel{\sim}{\uparrow}$ & $\stackrel{\sim}{T} 0$ & $0 \stackrel{\sim}{\uparrow} 0$ & $0 \stackrel{\sim}{\uparrow}$ & $\stackrel{\sim}{T} 0$ & $00 \stackrel{\sim}{T}$ \\
\hline & 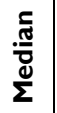 & $\simeq$ & $\underline{m}=$ & $\simeq \simeq \simeq$ & $\underline{m} \simeq$ & $\underline{m}$ 으 & 으 $\underline{m} \simeq$ \\
\hline \multirow{4}{*}{$\begin{array}{l}\breve{y} \\
\frac{\kappa}{z}\end{array}$} & 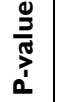 & & 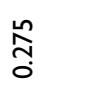 & $\underset{\substack{0 \\
\text { o }}}{ }$ & 守 & $\begin{array}{c}\text { O } \\
\infty \\
0 \\
0\end{array}$ & $\begin{array}{l}\frac{a}{\alpha} \\
\text { o. }\end{array}$ \\
\hline & $\underset{\Sigma}{\stackrel{x}{\Sigma}}$ & $\sim$ & No & $00 N$ & $-N$ & NO & $00 N$ \\
\hline & $\frac{\Sigma}{\Sigma}$ & $\varphi$ & น & † & $\varphi$ & $\stackrel{p}{p}$ & 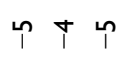 \\
\hline & 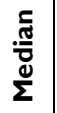 & $\top$ & $\top T$ & 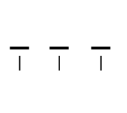 & T & T & $\top T \top$ \\
\hline \multirow{4}{*}{ 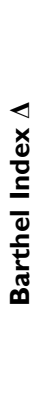 } & 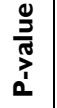 & & 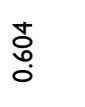 & 离 & 站 & \begin{tabular}{l}
$\infty$ \\
\multirow{2}{0}{} \\
0
\end{tabular} & $\stackrel{m}{\tilde{m}}$ \\
\hline & $\stackrel{\times}{\Sigma}$ & นก็ & นึ ๒ & 윤 늉ㅇ & 우 뉴 & ㄴํำ ํํ & 는 우 웃 \\
\hline & $\stackrel{\Sigma}{\Sigma}$ & $\uparrow$ & p & o ю & ค & i 0 & $00 p$ \\
\hline & $\frac{\frac{\pi}{\pi}}{\frac{\pi}{2}}$ & $\underline{\underline{n}}$ & 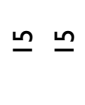 & $\underline{ } \underline{\underline{n}} \underline{\underline{n}} \underline{\underline{n}}$ & $\underline{\underline{n}} \underline{\underline{n}}$ & $\underline{ㄴ ㅡ} \underline{ }$ & $\underline{\underline{n}} \underline{\underline{1}} \underline{\underline{1}}$ \\
\hline \multicolumn{2}{|l|}{$\mathbf{z}$} & 똠 & 느 $=$ & बे & ఫั นૂ & 흐 뉴 & 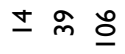 \\
\hline & & 厄ّٓ & $\stackrel{\frac{0}{\pi}}{\stackrel{0}{\tilde{J}}} \frac{0}{\Sigma}$ & 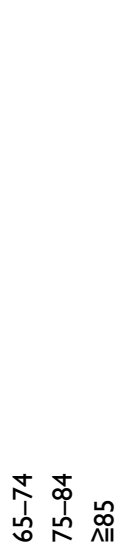 & 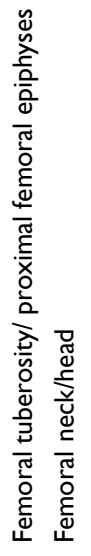 & 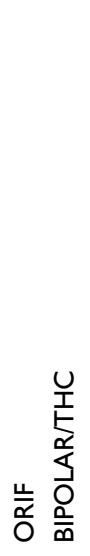 & $0-\lambda \Perp$ \\
\hline & & & $\stackrel{\times}{\oplus}$ & $\stackrel{\substack{\infty \\
<}}{<}$ & 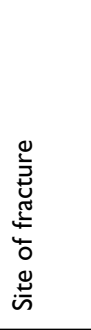 & 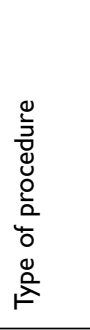 & 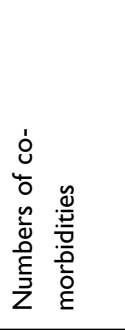 \\
\hline
\end{tabular}


Table 4 Analysis of Relationship Between Barthel Index, NRS, and HHS Using Pearson Product-Moment Correlation Coefficient

\begin{tabular}{|c|c|c|c|c|}
\hline \multicolumn{2}{|c|}{ Pre-PAC Score } & \multirow{3}{*}{ Barthel Index } & \multirow{3}{*}{$\begin{array}{l}\text { NRS } \\
0.01 \\
0.87\end{array}$} & \multirow{3}{*}{$\begin{array}{r}\text { HHS } \\
0.19 \\
0.01\end{array}$} \\
\hline Barthel Index & Pearson correlation coefficient & & & \\
\hline & $\mathrm{p}$-value & & & \\
\hline NRS & Pearson correlation coefficient & & I & -0.58 \\
\hline & $\mathrm{P}$-value & & & 0.000 \\
\hline $\mathrm{HHS}$ & $\begin{array}{l}\text { Pearson correlation coefficient } \\
\text { p-value }\end{array}$ & & & I \\
\hline \multicolumn{2}{|c|}{ Post-PAC Score } & Barthel Index & NRS & HHS \\
\hline \multirow[t]{2}{*}{ Barthel Index } & Pearson correlation coefficient & 1 & -0.33 & 0.44 \\
\hline & $\mathrm{p}$-value & & 0.000 & 0.000 \\
\hline \multirow[t]{2}{*}{ NRS } & Pearson correlation coefficient & & 1 & -0.64 \\
\hline & $\mathrm{P}$-value & & & 0.000 \\
\hline HHS & $\begin{array}{l}\text { Pearson correlation coefficient } \\
\text { p-value }\end{array}$ & & & I \\
\hline \multicolumn{2}{|l|}{ Scores $\Delta$} & Barthel Index & NRS & HHS \\
\hline \multirow[t]{2}{*}{ Barthel Index } & Pearson correlation coefficient & 1 & -0.12 & 0.21 \\
\hline & $\mathrm{p}$-value & & 0.13 & 0.01 \\
\hline \multirow[t]{2}{*}{ NRS } & Pearson correlation coefficient & & 1 & -0.35 \\
\hline & $\mathrm{p}$-value & & & 0.000 \\
\hline $\mathrm{HHS}$ & $\begin{array}{l}\text { Pearson correlation coefficient } \\
\text { p-value }\end{array}$ & & & I \\
\hline
\end{tabular}

It is essential to recognize the influence of comorbidities on hip fracture patients' functional and mortality outcomes. A three-year observational study presented that the number of comorbidities is significantly linked to increased mortality in 1- and 3-year follow up. ${ }^{16}$ While many reports on the Taiwan PAC program recognize comorbidities' presence impacts the recovery, no studies provided the actual number or the classification of comorbidities among their participants. In the present study, we demonstrated that most patients admitted to the PAC program had at least two comorbidities with hypertension and diabetes mellitus being the top two. Despite these comorbidities, subgroup analysis (Table 4) showed all outcome measures significantly improved after discharge.

In terms of the three critical parameters with PAC intervention, patients displayed a significant improvement in functional status (Barthel index), ameliorated pain (NRS), and enhanced hip performance (HHS). The initial Barthel index was $46.98 \pm 8.25$, which had increased to $62.74 \pm 12.49$ after the PAC program; this more than 15point change was statistically significant and clinically meaningful. Barthel's index score of 60 points marks the transitional point from severely ADL-dependent to moderate dependence. In a recent study on the Taiwan PACCVD program, the result also indicated an improvement in the functional status of at least one ladder on the Barthel index. ${ }^{17} \mathrm{~A}$ higher Barthel index is crucial in long-term outcomes as Folbert et al showed that functional status is linked to a decrease in 1-year mortality in the elderly after hip surgery. ${ }^{18}$

A similar result was found in a five-year prospective cohort study conducted in Taiwan; home- or institutionbased PAC improved patient's long-term survival (HR $2.79, \mathrm{p}=0.01$ ) and recovery of ADL. ${ }^{19}$ While this study was conducted between 2007 and 2009, before implementing the DRG bundled payment, and PAC rehabilitation structure was rudimentary. Nonetheless, the present study further strengthens the previous conclusion.

Moreover, a prospective study suggested that the preoperative Barthel index is an excellent prognostic factor for outcome after hip fracture. ${ }^{20,21}$ Authors propose that the Barthel index's usefulness as a prognostic predictor is 
not only limited to pre-operative assessment but also the post-operative (pre-PAC) and post-PAC values are also a valid indicator for favorable functional outcome in terms of HHS and NRS. Pre-PAC Barthel index is positive correlated to HHS (Pearson correlation coefficient $=0.19$, $\mathrm{p}<0.05$ ); Post-PAC Barthel index is negatively correlated to NRS (Pearson correlation coefficient $=-0.33, \mathrm{p}<0.01$ ) and positively to HHS (Pearson correlation coefficient $=$ 0.44, $\mathrm{p}<0.01)($ Table 3). Thus, a higher Barthel index predicts better hip joint functional outcomes and reduced pain at any point in time.

In the current treatment strategy post hip surgery in Taiwan, patients are encouraged to be mobile and independent in daily life activity as soon as possible. However, the health insurance reimbursement of this group of patients is valid less than 14 days. This might hamper the full recovery of the patients as they request more time and training during the hospitalization. The PAC program fills this gap and provide "galvanized version" of program for the post-surgery state (Routine rehabilitative program is to provide three times a week and less than 1 hour of training per session, as opposed to 6 times a week with 2 to 3 hour of targeted muscle training of the PAC program). In addition, the locations of PAC program are often satellite facility of the tertiary hospital and easily accessible to the patients. The well-rounded program enables patients' physical recovery in a carefree settings.

Severe limitations exist in the current study design and should be taken into account when interpreting the results. First of all, the current study was conducted in a PAC facility affiliated with a teaching hospital; therefore, the replicability is limited to similar settings. The nature of the current study is retrospective and observatory. There is no controlledgroup in the project. This could undermine the accuracy of the results of the data and data explanation. Additionally, the capacity and capability for rehabilitation in individual PAC facilities vary and should be taken into account when making the decision. Secondly, sampling bias was likely to exist in the current study since all subjects were recruited from the teaching hospital and required surgical intervention. The definition of readmission rate in the current manuscript varies among the hospitals in Taiwan. There is no general consensus as to the precise threshold of the value in this regard. This might potentially confuse the whole study. The authors are uncertain if the findings are similar in the elderly with hip fractures without an operation performed. Lastly, response bias may have occurred since the evaluation of
NRS is profoundly subjective, and it is challenging to standardize it.

\section{Conclusion}

A well-established rehabilitation program is essential in the recovery of functional status in patients with hip fracture surgery. The present form of post-surgery fragility fracture PAC program showed a drastic functional recovery with low re-admission rates comparable to the wellestablished PAC-CVD in Taiwan. The benefits in Barthel index, HHS, and reduction of the pain are present across all subgroups and are best seen after the first and second week of the program. This report provides up-to-date evidence in the new PAC program for the policymakers, physicians, and patients in Taiwan.

\section{Abbreviations}

ADL, Activity of daily living; BIPOLAR, Bipolar hemiarthroplasty; COPD, Chronic obstructive pulmonary disease; HHS, Harris Hip Scores; NRS, Numerical rating scale; ORIF, Open reduction internal fixation; PAC, Postacute care; PAC-CVD, Post-acute care cerebrovascular disease; THR, Total hip replacement; TW-DRG, Taiwan Diagnosis Related Groups.

\section{Data Sharing Statement}

The datasets used and/or analyzed during the current study are available from the corresponding author on reasonable request.

\section{Ethics Approval and Consent to Participate}

The Institutional Review Board (IRB) of Changhua Christian Hospital, approved this retrospective cohort study, which was performed in the Changhua Christian Hospital affiliated PAC facility. The study was retrospective in nature and the personal information of each patients has been decoded from the raw datasets upon data analysis and discussion. This part has been approved by the IRB of Changhua Christian Hospital, and waived the informed consent.

\section{Consent for Publication}

Written informed consent was obtained from the patient for publication of this retrospective cohort study. 


\section{Acknowledgments}

Yu-Jun Chang for the statistical analysis and support. JuLan Yang and Yang-Hao Ou are co-first authors for this study.

\section{Funding}

No funding was secured for this study.

\section{Disclosure}

The authors declare that they have no competing interests.

\section{References}

1. Veronese N, Maggi S. Epidemiology and social costs of hip fracture. Injury. 2018;49(8):1458-1460. doi:10.1016/j.injury.2018.04.015

2. Chie WC, Yang RS, Liu JP, et al. High incidence rate of hip fracture in Taiwan: estimated from a nationwide health insurance database. Osteoporos Int. 2004;15(12):998-1002. doi:10.1007/s00198-004-1651-0

3. Yi S, Chen MC, Liang J, Lu JF, Wu CC, Su JY. Changes in quality of life among elderly patients with hip fracture in Taiwan. Osteoporos Int. 2004;15(2):95-102. doi:10.1007/s00198-003-1533-x

4. Wang CB, Lin CF, Liang WM, et al. Excess mortality after hip fracture among the elderly in Taiwan: a nationwide population-based cohort study. Bone. 2013;56(1):147-153. doi:10.10 16/j.bone.2013.05.015

5. Tsuboi M, Hasegawa Y, Suzuki S, et al. Mortality and mobility after hip fracture in Japan: a ten-year follow-up. J Bone Joint Surg Br. 2007;89-B(4):461-466. doi:10.1302/0301-620X.89B4.18552

6. Chen F-P, Shyu Y-C, Fu T-S, et al. Secular trends in incidence and recurrence rates of hip fracture: a nationwide population-based study. Osteoporos Int. 2017;28(3):811-818. doi:10.1007/s00198-016-3820-3

7. Tosteson ANA, Gottlieb DJ, Radley DC, et al. Excess mortality following hip fracture: the role of underlying health status. Osteoporos Int. 2007;18(11):1463-1472. doi:10.1007/s00198-0070429-6

8. Wu SC. Subacute and post acute care: the bridge between acute and long-term care. J Nurs. 2008. doi:10.6224/JN.55.4.5

9. Wu S-C, Huang S-T, Wu C-F. Bundled payments for inpatient and post-acute care services in the United States. Taiwan J Public Health. 2014;33:459-469. doi:10.6288/TJPH201433103041

10. Han D-S. The demonstration on improving the quality of post-acute care in Taiwan National Health Insurance. New Taipei J Nurs. 2015;17(2):1-9. doi:10.6540/NTJN.2015.2.001
11. Kramer AM, Steiner JF, Schlenker RE, et al. Outcomes and costs after hip fracture and stroke: a comparison of rehabilitation settings. JAMA. 1997;277(5):396-404. doi:10.1001/jama.1997.03540290048031

12. Ding RY, Lin YCS, Huang KH, Chen YF, Kao MJ. Costeffectiveness analysis of post-acute rehabilitation program in patients with hip fracture. Airiti Lib Taipei City Med J. 2016. Available from: www.airitilibrary.com/Publication/alDetailedMesh? DocID= 18102549-201609-201610190005-201610190005-63-73. Accessed June 10, 2021

13. Hsieh C-Y, Tsao W-C, Lin R-T, et al. Three years of the nationwide post-acute stroke care program in Taiwan. $J$ Chin Med Assoc. 2018;81(1):87-88. doi:10.1016/j.jcma.2017.09.003

14. Karagas MR, Lu-Yao GL, Barrett JA, et al. Heterogeneity of hip fracture: age, race, sex, and geographic patterns of femoral neck and trochanteric fractures among the US elderly. Am J Epidemiol. 1996;143(7):677-682. doi:10.1093/oxfordjournals.aje.a008800

15. Lai C-L, Tsai -M-M, Luo J-Y, et al. Post-acute care for stroke a retrospective cohort study in Taiwan. Patient Prefer Adherence. 2017;11:1309. doi:10.2147/PPA.S136041

16. Uriz-Otano F, Pla-Vidal J, Tiberio-López G, et al. Factors associated to institutionalization and mortality over three years, in elderly people with a hip fracture - an observational study. Maturitas. 2016;89: 9-15. doi:10.1016/j.maturitas.2016.04.005

17. Chien S-H, Sung P-Y, Liao W-L, et al. A functional recovery profile for patients with stroke following post-acute rehabilitation care in Taiwan. J Formos Med Assoc. 2020;119(1):254-259. doi:10.1016/j. jfma.2019.05.013

18. Folbert EC, Hegeman JH, Vermeer M, et al. Improved 1-year mortality in elderly patients with a hip fracture following integrated orthogeriatric treatment. Osteoporos Int. 2017;28(1):269-277. doi:10.1007/s00198-016-3711-7

19. Peng L-N, Chen W-M, Chen C-F, Huang C-K, Lee W-J, Chen L-K. Survival benefits of post-acute care for older patients with hip fractures in Taiwan: a 5-year prospective cohort study. Geriatr Gerontol Int. 2016;16(1):28-36. doi:10.1111/ggi.12429

20. Simanski C, Bouillon B, Lefering R, Zumsande N, Tiling T. What prognostic factors correlate with activities of daily living (Barthel Index) 1 year after para-articular hip fracture? A prospective observational study. Der Unfallchirurg. 2002;105(2):99-107. doi:10.1007/ s001130100285

21. Pedersen TJ, Lauritsen JM. Routine functional assessment for hip fracture patients: are there sufficient predictive properties for subgroup identification in treatment and rehabilitation? Acta Orthop. 2016;87(4):374-379. doi:10.1080/17453674.2016.1197534
Therapeutics and Clinical Risk Management

\section{Publish your work in this journal}

Therapeutics and Clinical Risk Management is an international, peerreviewed journal of clinical therapeutics and risk management, focusing on concise rapid reporting of clinical studies in all therapeutic areas, outcomes, safety, and programs for the effective, safe, and sustained use of medicines. This journal is indexed on PubMed Central, CAS,
EMBase, Scopus and the Elsevier Bibliographic databases. The manuscript management system is completely online and includes a very quick and fair peer-review system, which is all easy to use. Visit http://www.dovepress.com/testimonials.php to read real quotes from published authors 